\title{
The preparation of dual-functional hydrogel as the surface coating of plastics in biomedical applications
}

\author{
Nan Zhao ${ }^{1}$, Bidhari Pidhatika ${ }^{2 *}$ \\ ${ }^{1}$ Laboratory for Chemistry and Physics of Interfaces, Department of Microsystems Engineering (IMTEK), Albert-Ludwigs-Universität Freiburg \\ (University of Freiburg), Georges-Koehler-Allee 103, 79110 Freiburg, Germany. \\ ${ }^{2}$ Center for Leather, Rubber and Plastics, Ministry of Industry, Jl. Sokonandi No. 9, 55166 Yogyakarta, Indonesia. \\ *Corresponding author. Tel.+62 274 512929, Fax. +62 274563655 \\ E-mail: pidhatika@kemenperin.go.id
}

Submitted: 19 September 2019 Revised: 29 November 2019 Accepted: 2 December 2019

\begin{abstract}
Poly(2-ethyl-2-oxazoline) (PEOXA) is among polymers that have been reported to show anti-adhesive (bio-passive) behavior in numerous biomaterial applications. This work aimed to develop dual-functional hydrogel coatings, with PEOXA as hydrophilic polymer and benzophenone as cross-linker. PEOXA was partially hydrolyzed in acidic conditions to form PEOXA-m\% EI that contains ethyleneimine (EI) groups. The EI groups were used as conjugation sites for incorporation of benzophenone (BP) molecules to PEOXA chains to form PEOXA-m\% EIBP. Thin films of surface-attached polymer networks were generated from PEOXA-m\% EIBP copolymers composed of PEOXA as platform and benzophenone as crosslinker units. The polymer became crosslinked through benzophenone units and forms a hydrogel as biopassive platform during irradiation with ultraviolet (UV) light. Laminin was incorporated into biopassive polymer network to allow for preparation of dual-functional hydrogel. NMR spectra indicated successful control of PEOXA partial hydrolysis and conjugation of benzophenone molecules to PEOXA chains. Ellipsometry and ATR-FTIR results showed that wavelength of UV light during C, H-insertion reaction influences stability of polymer network (hydrogel) on the substrate surface. XPS spectra verified that a stable film could be generated using suitable UV light during preparation of polymer network. Cell culture study on laminin/PEOXA-coated PMAA plastics showed dual-functional properties.
\end{abstract}

Keywords: biomedical, hydrogel, photo-crosslinker, plastics, poly(2-ethyl-2-oxazoline).

\section{INTRODUCTION}

Biomaterials, including biomedical devices, are materials in contact with living tissues and/or biological fluids (blood, urine, saliva, tears, etc.), intended to diagnose, replace, treat, or enhance the performance of particular organs/functions in the body. Examples of biomaterials are hip implants, urinary catheters, teeth implants, contact lenses, bio-sensors, and various surgical and medical devices. The more detailed description and classification of biomaterials are available in a review by Chen and Thouas (2015). Globally, there is an increasing demand for biomedical devices as life quality and life expectancy increase in this modern society. Both clinical demand and patient expectations will continue to grow (Holzapfel et al., 2013).

Despite their expected roles in increasing the life quality of patients, the contact of biomedical devices with a human body very often, if not always, trigger the fear of non-specific protein adsorption, bacterial infections, and foreign body response, in which the foreign objects with their artificial surfaces are not recognized by the mammalian cells, and thus treated as "stranger(s)" that must be removed/eliminated from the body (Castner \& Ratner, 2002). It was previously believed that any biomedical devices should present a biopassive surface, i.e., a surface that is bioinert, repellant to any biological entities and microorganisms to minimize the foreign body response. However, recent findings suggest that interactive, biomimetic surfaces are indeed required for enhancing biomaterials performance (Bellis, 2011).

It is now understood that implanted materials should not only provide structural support for damaged tissues, but also integrate with these tissues, and ideally, promote regeneration. Although the mechanisms are not yet wellunderstood, many researchers in the field of biomaterials are now striving to modify artificial surfaces with biologic elements to promote integration with surrounding tissues (Bellis, 2011). Thus, a scaffold that prevents non-specific interactions with non-targeted entities (biopassive/nonfouling/anti-adhesive) but enhances specific receptormediated cellular responses (bioactive) is in increasing demand in the field of tissue engineering.

The combination of bioactive moieties and the biopassive platform results in the so-called dual-functional surface coatings. In the context of tissue engineering, studies on dual-functional surface coatings have been previously reported (Chen et al., 2015; Loschonsky et al., 2008; Subbiahdoss et al., 2009; Subbiahdoss et al., 
2010). In particular, we have previously reported a dualfunctional hydrogel from combined poly(N, N-dimethyl methacrylate) (PDMAA) and laminin (Pidhatika et al., 2019b).

The presented work aimed at developing dualfunctional hydrogel coatings, in which poly(2-ethyl-2oxazoline) (PEOXA) (Pidhatika et al. 2019a) was chosen as the hydrophilic polymer and benzophenone were chosen as the cross-linker. Laminin was then covalently grafted to the hydrophilic (and biopassive) polymer network as the bioactive moiety. Finally, MCF-7 cells were cultured on the dual-functional films. Since numerous biomedical devices are made of plastics (Czuba, 2014; Padsalgikar, 2017; Sastri, 2014a; Sastri, 2014b; Sastri, 2014c; Sastri, 2014d), the dual-functional coating was studied on poly(methylmethacrylate) (PMMA) slide substrates. The reasons behind the selection of PEOXA as the biopassive platform, and laminin as the bioactive compounds are available in our previous publications (Pidhatika et al., 2019a; Pidhatika et al., 2019b). For the crosslinker, benzophenone is classified as a non-specific cross-linker that can bind to any $\mathrm{C}-\mathrm{H}$ bonds in its vicinity. This property of benzophenone offers a simple and effective process to covalently attach polymer layers to various solid surfaces using photo-irradiation method, as reported by Prucker et al., (1999). Dahm et al. (2001) used benzophenone monolayer to covalently bind various hydrophilic polymers onto glass slide surfaces. Not only for surface attachment, benzophenone was also used to fabricate (surface-attached) hydrogels, as reported by Murata et al. (2004). The kinetics of the generation of surface-attached polymer networks containing benzophenone cross-linker units through $\mathrm{C}-\mathrm{H}$ insertion reactions has been studied systematically (Körner et al., 2016). The success story of benzophenone as a photo reactive cross-linker to fabricate as well as covalently deposit polymer networks simply and effectively for numerous, wide-ranging, applications is still continuously reported until very recently (Kleber $e t$ al., 2017; Scherag et al., 2017; Schuler et al., 2016).

Different from our previous publication (Pidhatika et al., 2019b) where PDMAA was used as the biopassive platform, the presented work focuses on PEOXA as the biopassive platform. Furthermore, different from our other previous publication (Pidhatika et al., 2019a) where the potency of the PEOXA network as biopassive platform was evaluated, the presented work provides more details on the synthesis and bulk characterization of benzophenonebearing PEOXA, as well as on surface characterization of the hydrogel. Moreover, the PEOXA biopassive network was combined with laminin as a bioactive compound.

Characterization of synthesized polymers was performed using nuclear magnetic resonance spectroscopy (NMR). Characterization of immobilized hydrogel on the surface was performed through ellipsometry, attenuated total reflectance - Fourier transform infrared spectroscopy (ATR-FTIR), and X-ray Photoelectron Spectroscopy (XPS). Finally, the dual-functional hydrogel was prepared on PMMA plastics substrates, followed by characterization using cell culture and optical microscopy. A similar polymer has been reported by other researchers (Dhende et al., 2011; Lambermont-Thijs et al., 2010; Li et al., 2019). However, to the best of our knowledge, none of their reports provided the details as highlighted in this report.

\section{MATERIALS AND METHODS Materials}

Poly(2-ethyl-2-oxazoline) (PEOXA) $50 \mathrm{kDa}$, 4-(bromomethyl) benzophenone, organic solvents, and physiological buffer were purchased from SigmaAldrich. MCF-7 cells were provided by the Laboratory for Bioinformatics and Molecular Genetics, Biology Department, University of Freiburg. Triethoxybenzophenone silane was synthesized from triethoxysilane and 4-allyloxybenzophenone, and provided by the Laboratory for Chemistry and Physics of Interfaces. Silicon wafer and poly(methylmethacrylate) (PMAA) substrates were purchased from Thermo Fisher Scientific.

\section{Methods}

All synthesized polymers were characterized using ${ }^{1} \mathrm{H}-\mathrm{Nuclear}$ Magnetic Resonance Spectroscopy ( $\left.{ }^{1} \mathrm{H}-\mathrm{NMR}\right)$. Prior to immobilization, crosslinking, and characterization on plastics (PMMA) surfaces, the formation of polymer network and its performance were investigated on modified silicon wafers. X-ray Photoelectron Spectroscopy (XPS) enabled the determination of chemical composition. Ellipsometry and Atomic Force Microscopy (AFM) enabled the determination of hydrogel film thickness, gel content, and stability. Cell culture study and phasecontrast microscopy on hydrogel-coated plastics substrates determines the aimed dual-functional properties of the hydrogel. The following protocols were adapted from previous reports (Pidhatika et al., 2019a; Pidhatika et al., 2019b).

\section{Preparation of silicon wafer substrate with $\mathrm{C}-\mathrm{H}$ bonds on its surface}

PEOXA-11\% EIBP was dissolved in ethanol (50 or $100 \mathrm{mg} / \mathrm{ml}$ ) and filtered through a $0.45 \mu \mathrm{m}$ filter. The polymer solution stock was stored at $4{ }^{\circ} \mathrm{C}$ and pre-warmed up to room temperature before use. Silicon wafer was cut (typically $1.5 \times 1.5 \mathrm{~cm}$ ) and cleaned with isopropanol, toluene, ethanol, and acetone. After drying with nitrogen, triethoxy-benzophenone silane was spin-coated (600 rpm, $100 \mathrm{~s}$ ) on top of the wafer. The wafer was then heated up to $120^{\circ} \mathrm{C}$ on a hot plate for $30 \mathrm{~min}$. After cooling down to room temperature, the wafer was thoroughly rinsed with toluene to remove un-attached triethoxy-benzophenone silane, followed by blow-drying under Nitrogen.

\section{Hydrogel formation, immobilization, and stability}

Hydrogel formation, immobilization, and stability study were performed following the previously published protocol (Pidhatika et al., 2019a). The polymer solution was spin-coated on top of the above-described wafer. The 
polymer was irradiated under UV light in a Stratalinker ${ }^{\circledR}$ UV crosslinker, followed by rinsing with dissolving solvent and blow-drying under nitrogen. The wafer was then incubated in a physiological buffer (in this case PBS was used). After $24 \mathrm{~h}$, the wafer was thoroughly washed with aquadest and ethanol, followed by blow-drying under nitrogen. The film thickness was measured using ellipsometry (thickness $t_{1}$ ). The prolonged incubation time of the wafer in the buffer, up to 30 days, was applied to investigate the hydrogel stability. The film thickness was measured from time to time, resulting in thickness $t_{n}$, where $\mathrm{n}$ is $1,2,3, \ldots, 30$. The remaining thickness was calculated according to equation 1 . The chemical characterization was performed by means of ATR-FTIR and XPS spectroscopy.

$$
\text { Remaining thickness }=\frac{t_{n}}{t_{1}} \times 100 \%
$$

\section{Cell culture study}

Cell culture study was performed following the previously published protocol (Pidhatika et al., 2019b). PEOXA-11\% EIBP polymer solution with a concentration of $50 \mathrm{mg} / \mathrm{ml}$ in ethanol was spin-coated $(600 \mathrm{rpm}, 100$ s) onto a PMMA slide. The slide was placed inside a petri dish after spin-coating. After pre-irradiation of PEOXA-11\% EIBP with UV light at $365 \mathrm{~nm}$, the petri dish was taken out of the UV crosslinker (Stratalinker ${ }^{\circledR}$ ). Laminin was drop-coated on top of the polymer layer and the crosslinking process was continued. To keep the hydrogel sterile, antibacterial sodium azide was added to PBS buffer that will be used to incubate the hydrogel. The concentration of sodium azide in the PBS was $0.1 \% \mathrm{v} / \mathrm{v}$. Then, $3 \mathrm{ml}$ of the PBS was placed inside the petri dish and left for $24 \mathrm{~h}$. Next, the petri dish was twice rinsed and thoroughly washed with pure PBS to remove traces of sodium azide (possibly toxic to cells). MCF-7 cells in a cell medium were then cultured on the modified-PS surface inside the petri dish. After $24 \mathrm{~h}$ of cell culture on the modified-surfaces, the cell adhesion was observed using phase-contrast microscopy.

\section{RESULTS AND DISCUSSION}

The presented work focused on the preparation of dual-functional hydrogel as coating on plastics (polymeric) surfaces for biomedical applications. Figure 1 illustrates the strategy to achieve the objective. In this work, PMMA was used as the plastics substrates, benzophenone as the photocrosslinker, PEOXA as the hydrophilic (biopassive) polymers, and laminin as the cell adhesive (bioactive) molecules.

\section{Synthesis and Characterization of Poly(2-ethyl-2- oxazoline)-m\% ethyleneimine}

Poly(2-ethyl-2-oxazoline)- $\mathrm{m} \%$

ethyleneimine (PEOXA-m\% EI) was synthesized by partially hydrolyzing PEOXA in acidic conditions, following previously published protocol (Figure 2) (Dhende et al., 2011; Lambermont-Thijs et al., 2010).

The characterization of the resulting PEOXA-m\% EI was performed using Nuclear Magnetic Resonance spectroscopy (NMR). Figure 3, 4a, and $4 b$ show the ${ }^{1} \mathrm{H}$ NMR spectrum acquired from PEOXA, PEOXA-6\% EI, and PEOXA- $80 \%$ EI, respectively. The decrease of the peak $a$ and $b$ also the increase of peak $d$ in the spectra when comparing the three Figures (3, $4 \mathrm{a}$, and $4 \mathrm{~b})$ demonstrated the increase of hydrolysis degree of the PEOXA chain. Figure 5 shows the degree of hydrolysis as a function of reaction time, as obtained in this study. As expected, the degree of hydrolysis increased with an increase in reaction time.

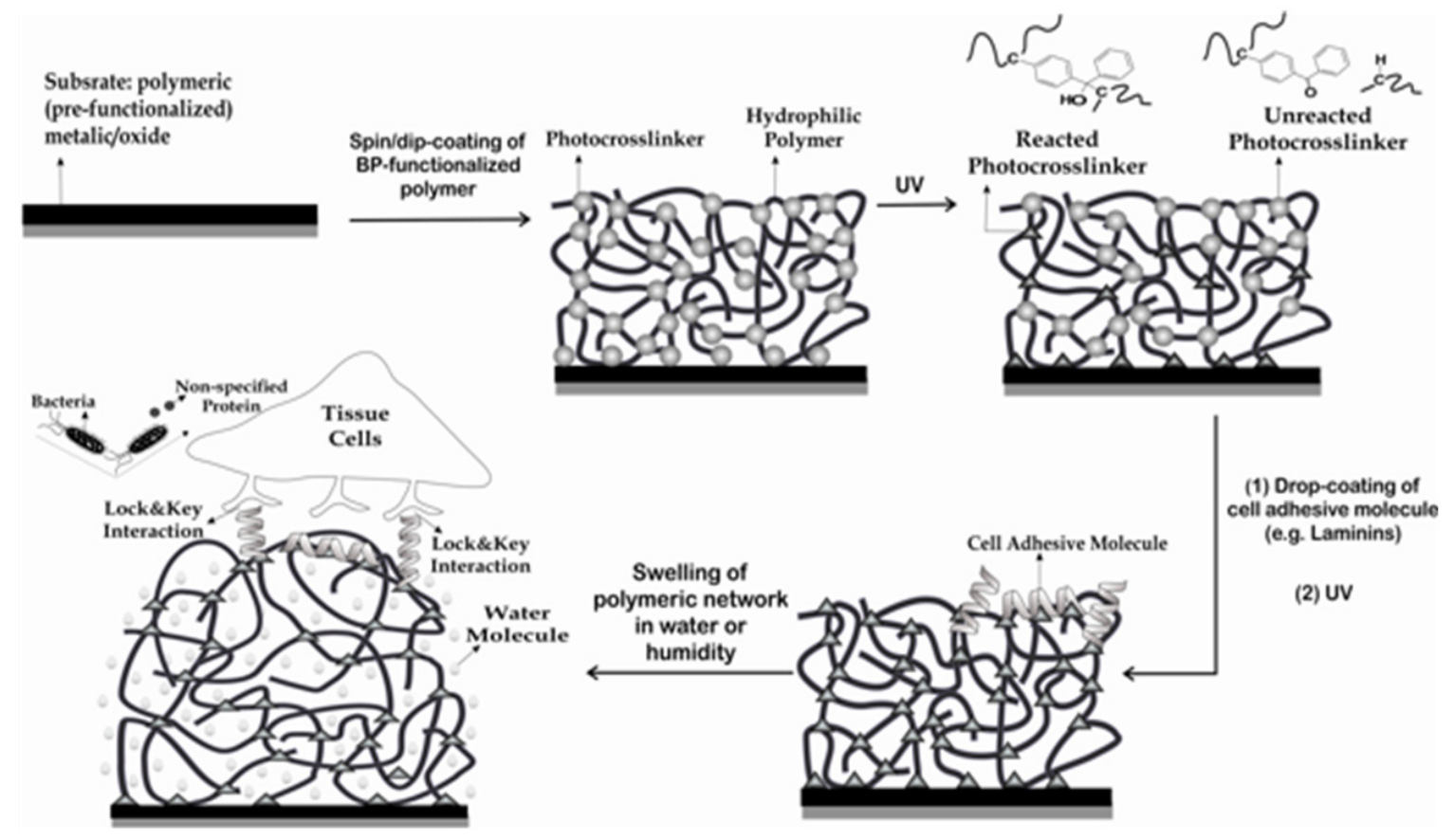

Figure 1. The strategy on the preparation of dual-functional hydrogel on plastics (polymeric) surfaces (Pidhatika et al., 2019b). 
Synthesis and Characterization of Poly(2-ethyl-2oxazoline)-m\% Ethylene Imine Benzophenone

The 4-(bromomethyl) benzophenone was then grated to either PEOXA-6\% EI or PEOXA-11\% EI, using the protocol reported by Dhende et al. (2011). The synthesis route is depicted in Figure 6, and it was performed in tertiary amyl alcohol.

The characterization of the resulting poly(2ethyl-2-oxazoline)-m\% ethylene imine benzophenone (PEOXA-m\% EIBP) was performed using Nuclear Magnetic Resonance spectroscopy (NMR). Figures $7 \mathrm{a}$ and $7 \mathrm{~b}$ show the ${ }^{1} \mathrm{H}-\mathrm{NMR}$ spectrum acquired from PEOXA-6\% EIBP and PEOXA-11\% EIBP, respectively. As expected, peaks d, e, and $\mathrm{f}$ (relative to peak c) in Figure $7 \mathrm{~b}$ show higher intensities compared to those in Figure $7 \mathrm{a}$, due to the higher amount of EIBP content in PEOXA$11 \%$ EIBP.

In addition to ${ }^{1} \mathrm{H}-\mathrm{NMR},{ }^{13} \mathrm{C}-\mathrm{NMR}$ was performed to PEOXA-11\%EIBP. The resulting ${ }^{13} \mathrm{C}-\mathrm{NMR}$ spectrum of PEOXA-11\% EIBP was then compared to that of PEOXA$11 \%$ EI (Figure $8 \mathrm{a}$ and $\mathrm{b}$ ). In addition to peaks a, b, c, d, and $g$ in Figure $8 \mathrm{a}$, the ${ }^{13} \mathrm{C}$ peaks $\mathrm{e}$, $\mathrm{f}$, and h originated from the methyl benzophenone group were detected in Figure 8 b. Combined with the ${ }^{1} \mathrm{H}-\mathrm{NMR}$ spectra, the ${ }^{13} \mathrm{C}-\mathrm{NMR}$ spectra demonstrate the success of the benzophenone grafting to the PEOXA-11\% EI chains.
Immobilization of the Benzophenone-functionalized PEOXA on the Surface, Hydrogel Formation, and Stability

After systematic study and validation of successful polymer synthesis using ${ }^{1} \mathrm{H}$ - and ${ }^{13} \mathrm{C}-\mathrm{NMR}$ characterization method, PEOXA-11\% EIBP was used to modify the surface of plastics material (in this case PMMA), according to the strategy as depicted in Figure 1. Upon irradiation under UV light, the benzophenone groups react according to C, H-insertion mechanism (Körner et al., 2016), as illustrated in Figure 1, leading to crosslinking and polymer network (hydrogel) formation on the substrate surface. Simultaneously with polymer network formation, covalent immobilization took place, provided that $\mathrm{C}-\mathrm{H}$ bonds are available on the substrate surface.

Since PMMA is an organic compound, abundant $\mathrm{C}-\mathrm{H}$ bonds are available on its surface. However, the methods (ellipsometry for film thickness measurements and FTIR for functional group detections) that can be used to characterize the properties of surface-attached hydrogel require substrate properties that cannot be provided by plastics materials. Thus, before immobilization to PMMA surface for validation of dual-functional properties, the PEOXA-11\% EIBP polymer was immobilized on silicon wafers that were modified with an ultrathin film of organic compound (triethoxy-benzophenone silane) that contains

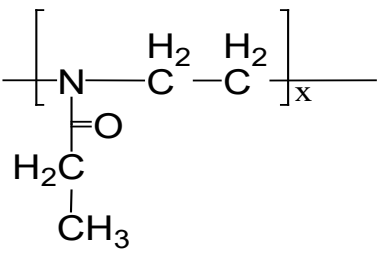

(1)

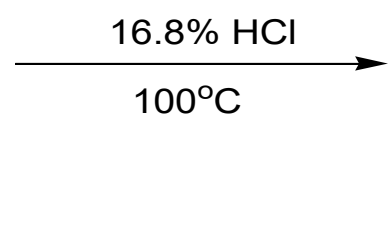

Note:

(1): Poly(2-ethyl-2-oxazoline): PEOXA

(2): Poly(2-ethyl-2-oxazoline)-m\%poly(ethyleneimine): PEOXA-m\% EI

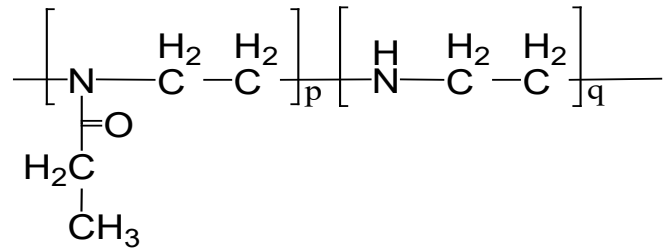

(2)

Figure 2. The acidic partial hydrolysis of PEOXA to PEOXA-m\% EI.

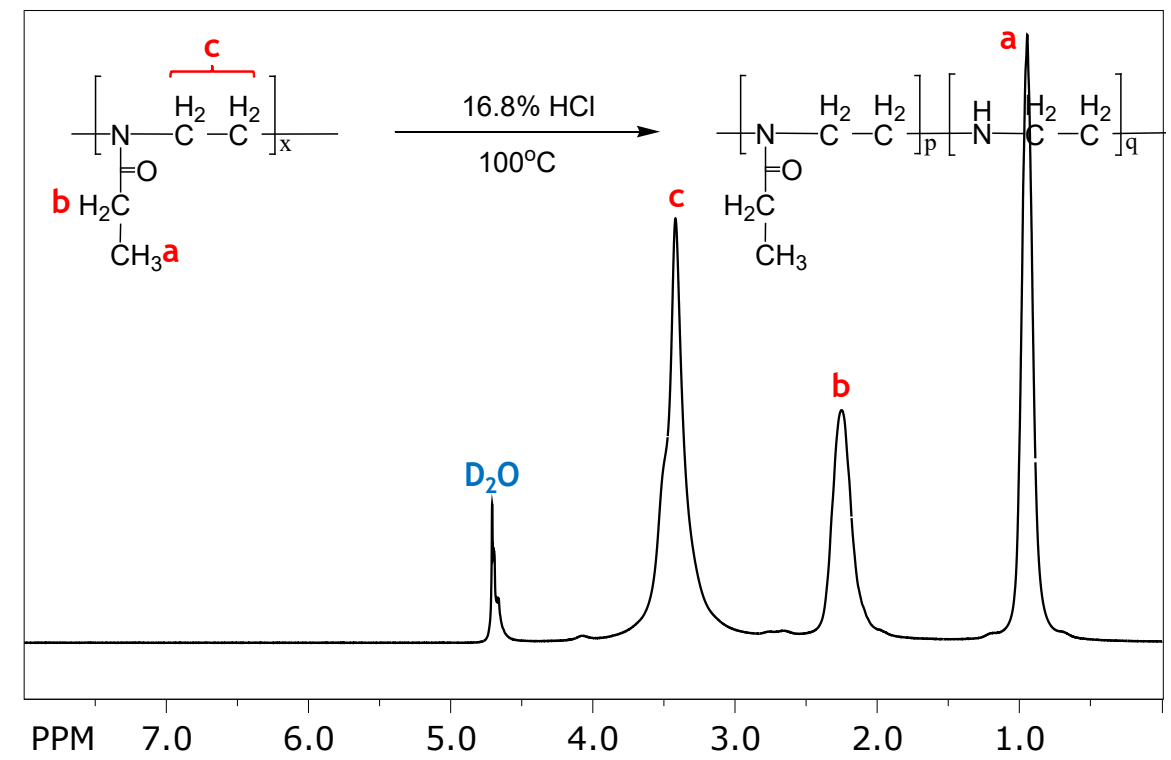

Figure 3. The typical ${ }^{1} \mathrm{H}-\mathrm{NMR}$ spectrum of PEOXA. 
sufficient $\mathrm{C}-\mathrm{H}$ bonds like plastics surfaces. This strategy allowed for investigation on the initial and remaining thickness of hydrogel film after certain incubation time in relevant medium, i.e., determination of film stability, using ellipsometry method that requires reflecting substrates (McCrackin et al., 2001).

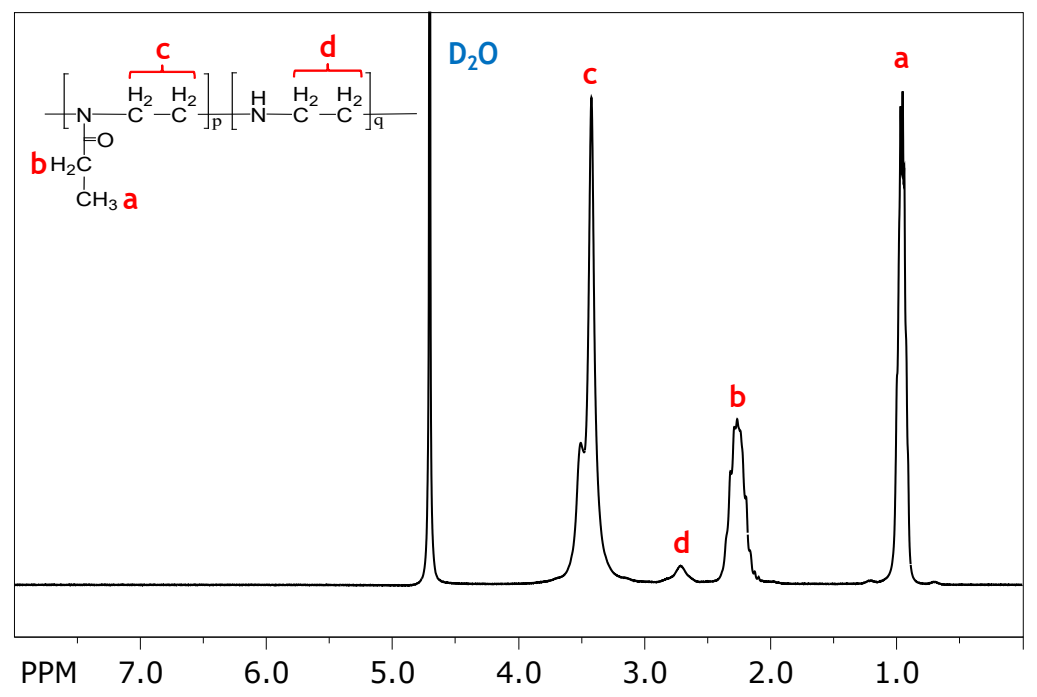

(a)

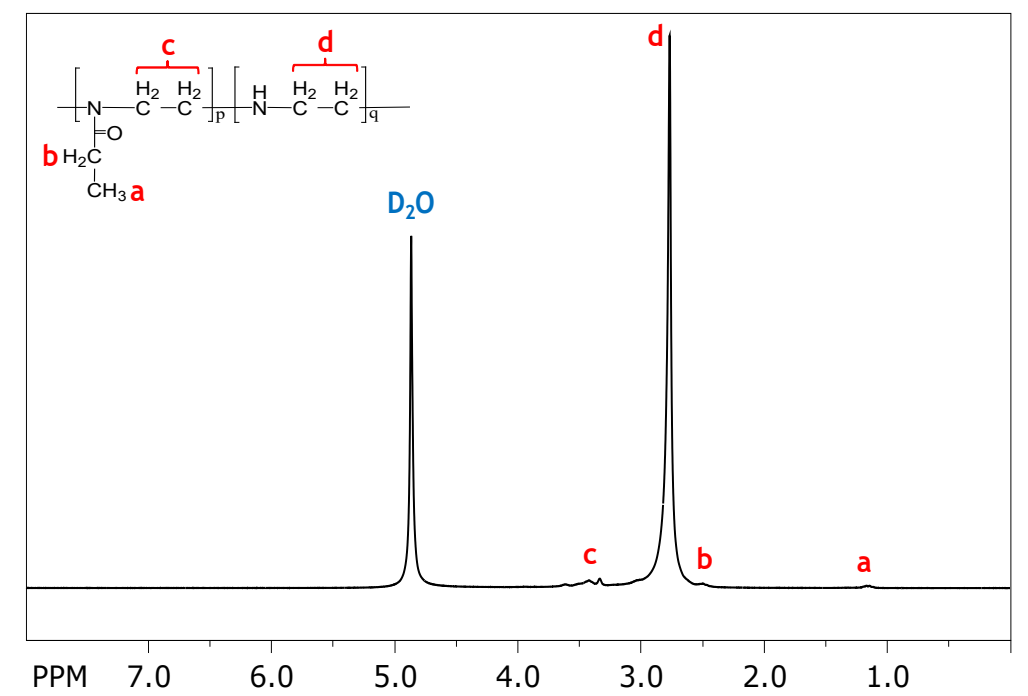

(b)

Figure 4. The typical ${ }^{1} \mathrm{H}-\mathrm{NMR}$ spectrum of a) PEOXA-6\% EI, and b) PEOXA-80\% EI.

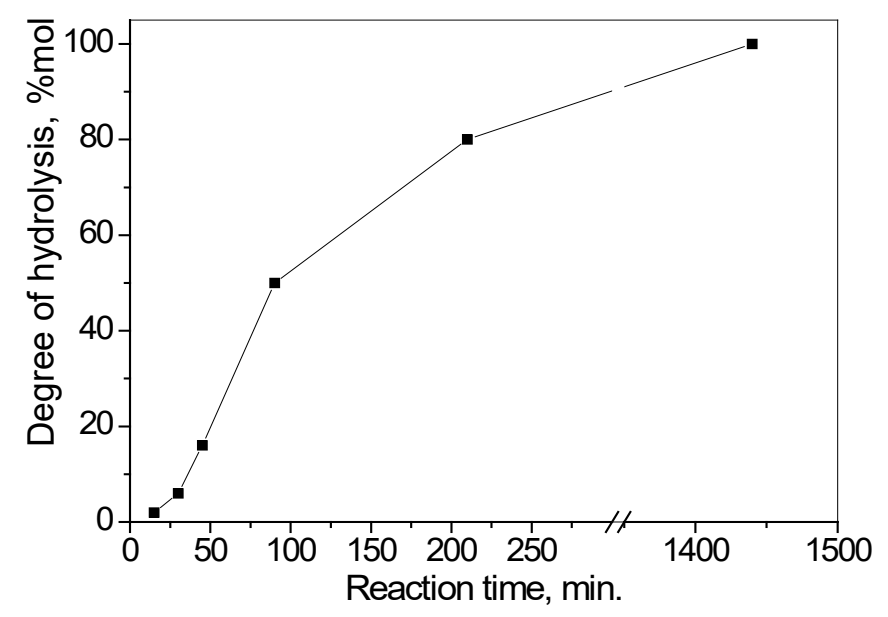

Figure 5. Degree of hydrolysis of PEOXA as a function of time, in acidic condition, with an excess amount of $\mathrm{HCl}$ relative to the amide concentration. 
In this study, 2 (two) wavelengths of UV light, i.e., 254 and $365 \mathrm{~nm}$, were used to irradiate the surface-coated polymer chains containing benzophenone units. In many applications, certain stability of the hydrogel layer is required. Thus, the hydrogel film was then exposed to an environment that is relevant to the targeted application, i.e., PBS (physiological buffer) that was also used during the cell culture study (discussed later in this report). The (dry) film thickness was measured from time to time using ellipsometry, and the remaining thickness was calculated relative to the layer thickness after 1 (one)-day exposure time. The results from the stability test are shown in Figure 9.

It is seen in Figure 9 that hydrogel prepared using UV light irradiation at $254 \mathrm{~nm}$ was less stable compared to hydrogel prepared using UV light irradiation at 365

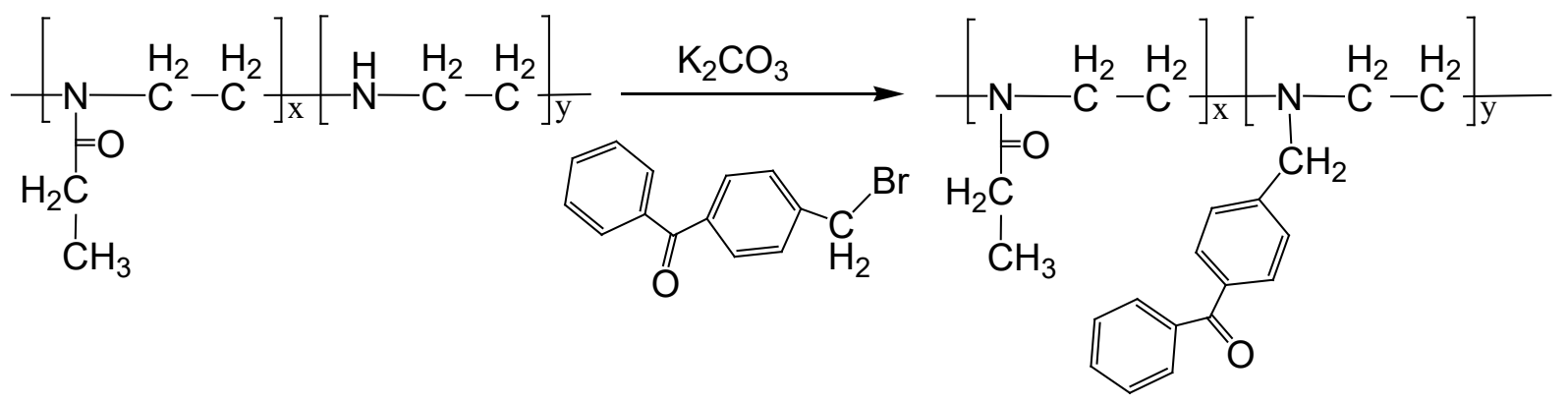

(1)

(2)

(3)

Note:

(1): PEOXA-m\% EI

(2): 4-(bromomethyl) benzophenone

(3): Poly(2-ethyl-2-oxazoline)-m\% ethyleneiminebenzophenone (PEOXA-m\% EIBP)

Figure 6. The grafting reaction of 4-(bromomethyl) benzophenone to PEOXA-m\% EI.

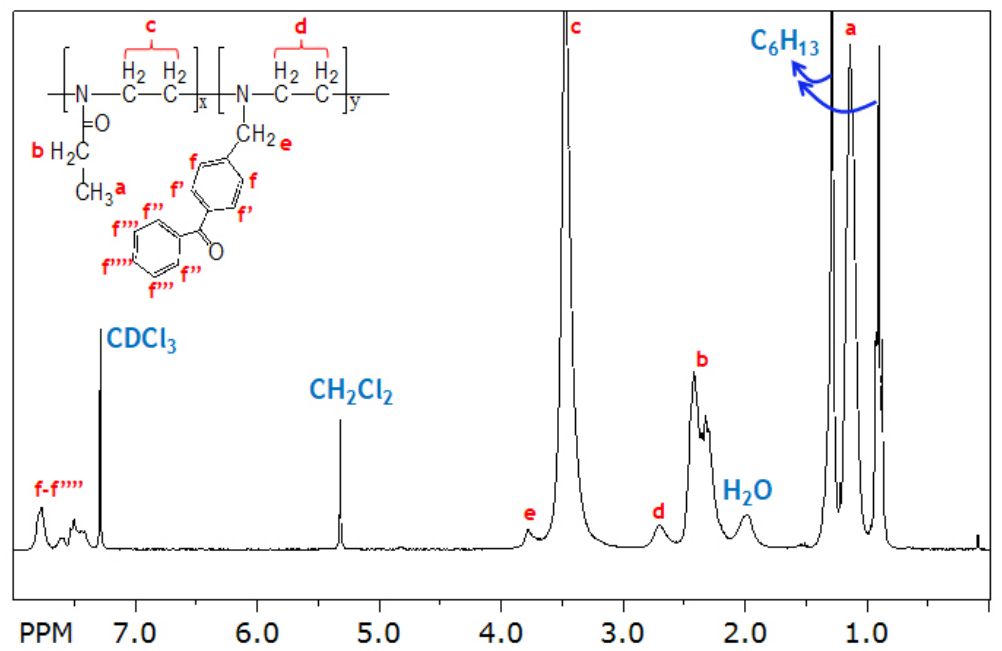

(a)

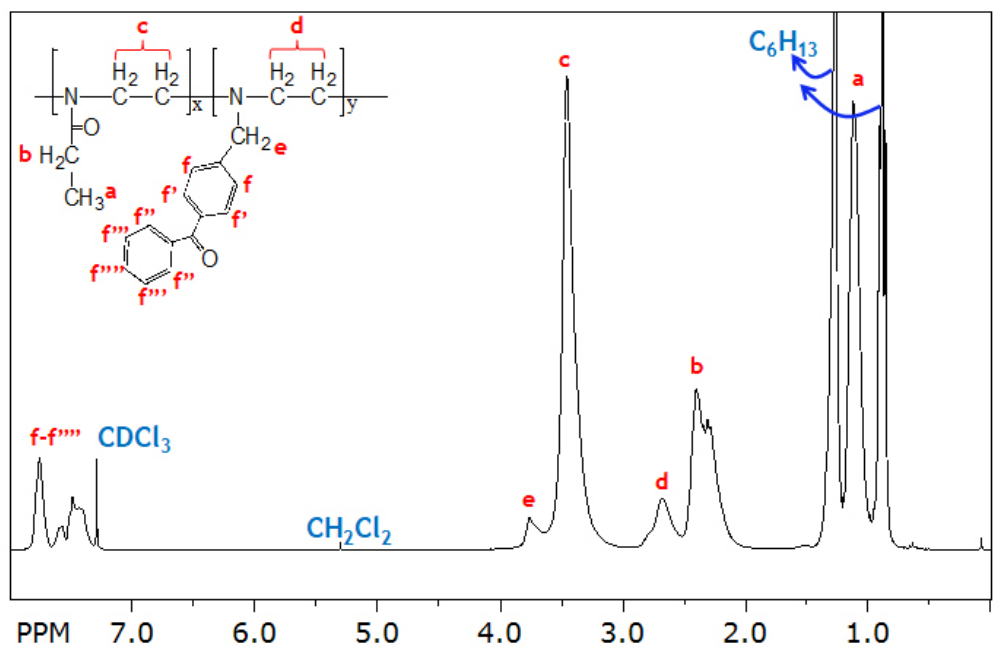

(b)

Figure 7. The typical ${ }^{1}$ H-NMR spectrum of a) PEOXA-6\% EIBP and b) PEOXA-11\% EIBP (Pidhatika et al., 2019a). 
$\mathrm{nm}$. The initial film thickness was approximately $700 \mathrm{~nm}$. It is worthwhile to note that UV light irradiation energy increases with a decrease in its wavelength. In agreement with our previous finding, UV light at lower wavelength accelerates polymer degradation due to its too high energy (Pidhatika et al., 2019a).
In addition to ellipsometry method that measures film thickness, attenuated total reflectance-fourier transform infrared spectroscopy (ATR-FTIR) measurements were performed in attempts to probe changes of the chemical structure of the polymer during crosslinking reactions and network formation and to gain understanding on the

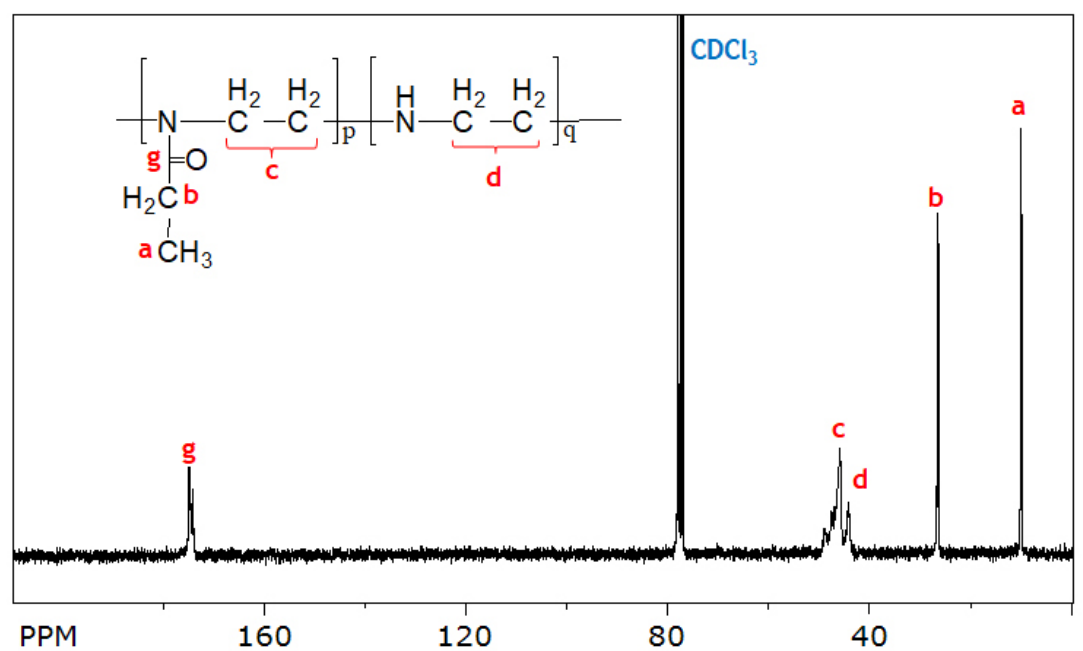

(a)

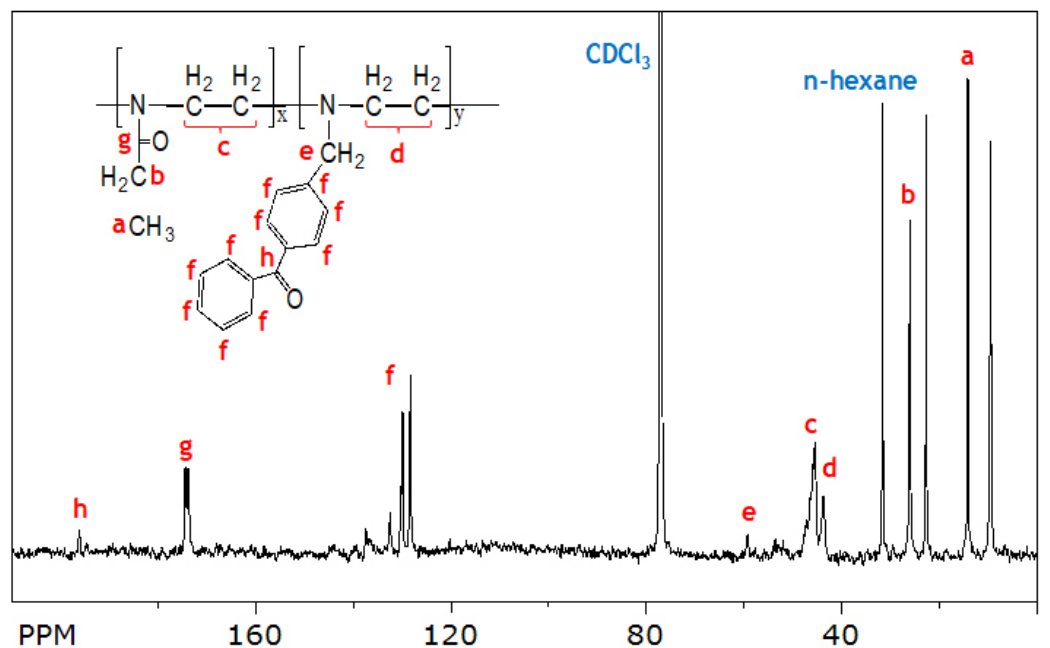

(b)

Figure 8. The typical ${ }^{13} \mathrm{C}-\mathrm{NMR}$ spectrum of a) PEOXA-11\% EI compared to b) PEOXA-11\% EIBP.

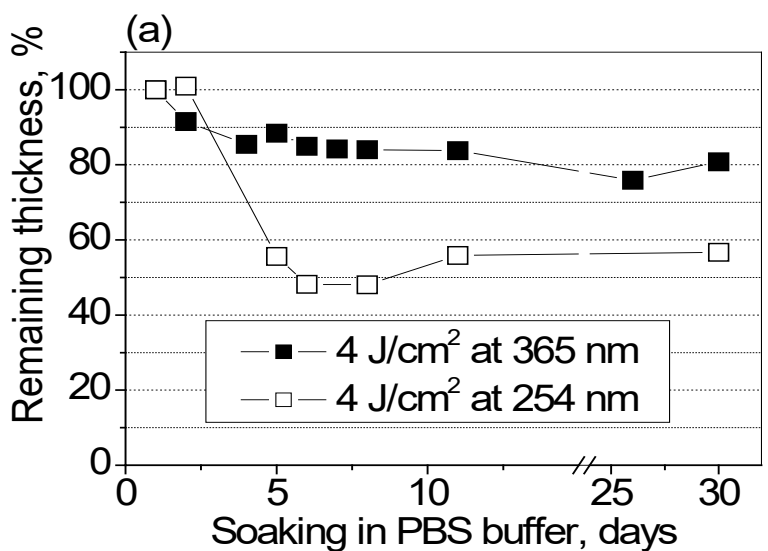

Figure 9. The remaining thickness of PEOXA-11\% EIBP film as a function of exposure time to the PBS buffer for a different wavelength of UV light during crosslinking reaction. 
reason of hydrogel instability under UV light irradiation at a lower wavelength. Figure 10 shows the change of FTIR spectra of the spin-coated PEOXA-11\% EIBP layer on a modified silicon wafer during UV light irradiation at 254 $\mathrm{nm}$ and $365 \mathrm{~nm}$.

It was seen that UV light irradiation at $254 \mathrm{~nm}$ led to more extreme changes (at wavenumber around 3000$3500 \mathrm{~cm}^{-1}$ and $1500-1750 \mathrm{~cm}^{-1}$ ) of the FTIR spectra of the PEOXA-11\% EIBP film, which means more changes in the chemical structure and functional groups of the film. On the other hand, only slight changes were observed in the spectra of the layer upon UV irradiation at $365 \mathrm{~nm}$, even up to $16.4 \mathrm{~J} / \mathrm{cm}^{2}$ of the irradiation energy. This phenomenon indicated that UV light at $254 \mathrm{~nm}$ is significantly more powerful to activate the benzophenone than at $365 \mathrm{~nm}$, but might also be more destructive to the polymer as a whole. The latter was evident from the stability measurements (discussed in the earlier section), that UV light irradiation at $254 \mathrm{~nm}$ resulted in significantly lower hydrogel stability. Interestingly, no significant changes were observed in both PEOXA and PEOXA-11\% EI spectra upon UV light irradiation at $254 \mathrm{~nm}$ and $365 \mathrm{~nm}$ respectively. Based on this finding, UV light at $365 \mathrm{~nm}$ was used for the hydrogel preparation on plastics surfaces.

The stability of hydrogel film on the surface when prepared using suitable condition was further validated using another surface characterization method, i.e., X-ray Photoelectron Spectroscopy (XPS). For XPS measurements, PEOXA-11\% EIBP was spin-coated on silicon wafers as XPS substrate modified with the ultrathin film of organic compound that contained sufficient $\mathrm{C}-\mathrm{H}$ bonds like plastics surfaces. According to the strategy as illustrated in Figure 1, irradiation of the film with UV light at $365 \mathrm{~nm}$ should form a polymer network (hydrogel film) that strongly attached to the surface. XPS measurements were then performed on the following surfaces, i.e., 1) bare XPS substrate (silicon wafer), 2) spin-coated PEOXA-11\% EIBP film, and 3) spin-coated PEOXA-11\% EIBP film after UV light irradiation at $365 \mathrm{~nm}$ followed by incubation in physiological (PBS) buffer for 14 days.

While the survey XPS spectra of these surfaces have been reported in our previous publication (Pidhatika et al., 2019a), here we present the high resolution XPS spectra. Figure 11 shows the deconvolution of high resolution $\mathrm{C} 1 \mathrm{~s}$, $\mathrm{N} 1 \mathrm{~s}$, and O 1s XPS spectra of the three above-mentioned surfaces. The bare silicon wafer substrate (Figure 11(a)(c)) shows the typical carbon contamination ( $\mathrm{C}$ aliphatic, $\mathrm{C}-\mathrm{O}$, and $\mathrm{O}-\mathrm{C}=\mathrm{O}$ ) and an oxygen signal originating from the silicon oxide (Si-ㅁ), while nitrogen-containing species was absent. Spin-coating of PEOXA-11\% EIBP on top of

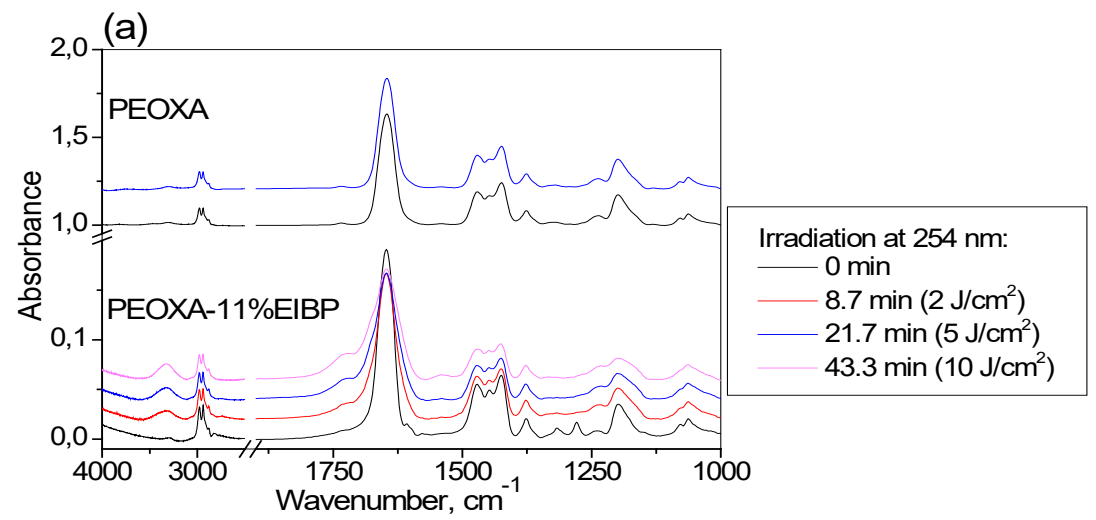

(a)

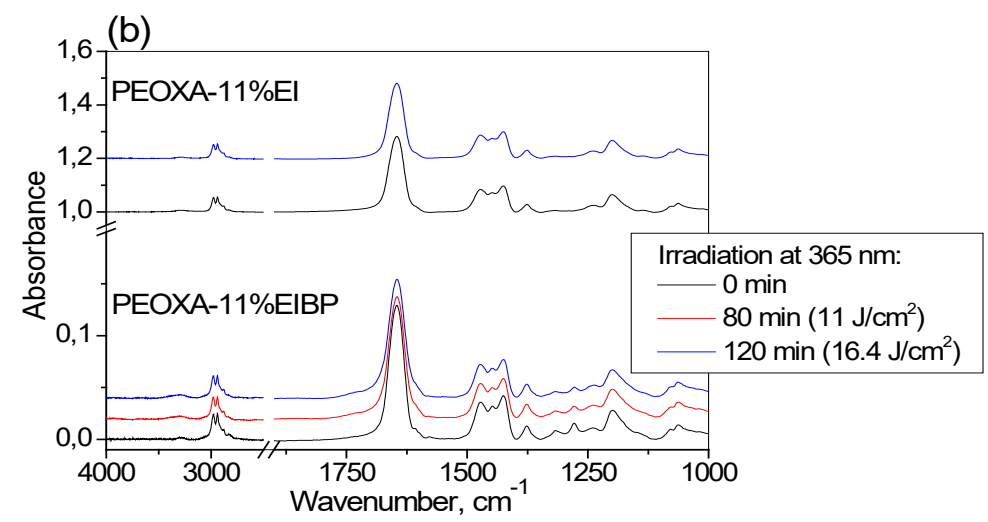

(b)

Figure 10. FTIR spectra of a) PEOXA (above) and PEOXA-11\% EIBP (below) upon different UV light irradiation dose at $254 \mathrm{~nm}$, and b) PEOXA-11\% EI (above) and PEOXA-11\% EIBP (below) upon different UV light irradiation dose at $365 \mathrm{~nm}$. 
the (silanized) silicon wafer resulted in the domination of the spectra by PEOXA repeating units (Figure 11(d)-(f)).

Most prominently, a strong nitrogen signal due to the amide bonds (C-N) was observed. Correspondingly, the deconvolution of $\mathrm{C} 1 \mathrm{~s}$ peak resulted in 3 (three) peaks, with 4 (four) components $\left(\mathrm{C}-\underline{\mathrm{C}}=\mathrm{C}, \mathrm{H}_{3} \underline{\mathrm{C}}-\mathrm{C}, \mathrm{C}-\underline{\mathrm{C}}-\mathrm{N}, \mathrm{O}=\underline{\mathrm{C}}\right)$. Only 1 (one) oxygen signal $\mathrm{C}=\underline{\mathrm{O}}$ was observed. Irradiation of the spin-coated PEOXA-11\% EIBP (Figure 11(g)-(i)) resulted in the decrease of $\mathrm{O}=\underline{\mathrm{C}}$ and increase of $\mathrm{C}-\underline{\mathrm{C}}-\mathrm{C}$ signal under the $\mathrm{C} 1 \mathrm{~s}$ peak. In addition, the second oxygen species (C-ㅁH) appeared. Both observed phenomena (in C 1s and $\mathrm{O} 1 \mathrm{~s}$ ) indicated the network formation of the polymer film due to the $\mathrm{C}, \mathrm{H}$-insertion reaction of benzophenone groups. Importantly, no significant changes in N/C signal intensity ratio between the two latter surfaces, which indicated the hydrogel film stability upon exposure to physiological buffer for 14 days.

Immobilization of Cell culture on Dual-functional PEOXA-based Hydrogel on PMMA Substrate

After systematic study and validation of hydrogel immobilization, formation, and stability, the PEOXA-
$11 \%$ EIBP polymer was coated on PMMA substrate. In addition to PEOXA-11\% EIBP that should play role as biopassive platform, cell adhesive molecule was added to the film to provide bioactivity. The combined biopassive and bioactive properties should result in dual-functional hydrogel as coating on plastics surfaces for biomedical applications. The strategy (with 2 (two)-step UV light irradiation) was previously illustrated in Figure 1. Briefly, to obtain a dual-functional surface, cell adhesive locations need to be generated on the surfaces. To achieve this, the photoreaction during hydrogel generation was stopped before complete conversion of the photoactive groups. Onto this layer, laminin as a well-known cell adhesion protein was drop-coated and the photo activation process continued, led to formation of a layer of covalently bound laminin. Figure 12 shows the microscopy images of laminin - PEOXA-11\% EIBP (inside the circled area) and PEOXA-11\% EIBP (outside the circled area) - coated surfaces, after exposure to MCF-7 cells.

The films were prepared using different UV light irradiation dose, after exposure to MCF-7 cells for $24 \mathrm{~h}$. The laminin ( $1 \mathrm{mg} / \mathrm{ml}$ in PBS buffer, $2 \mu \mathrm{l})$ was drop-coated
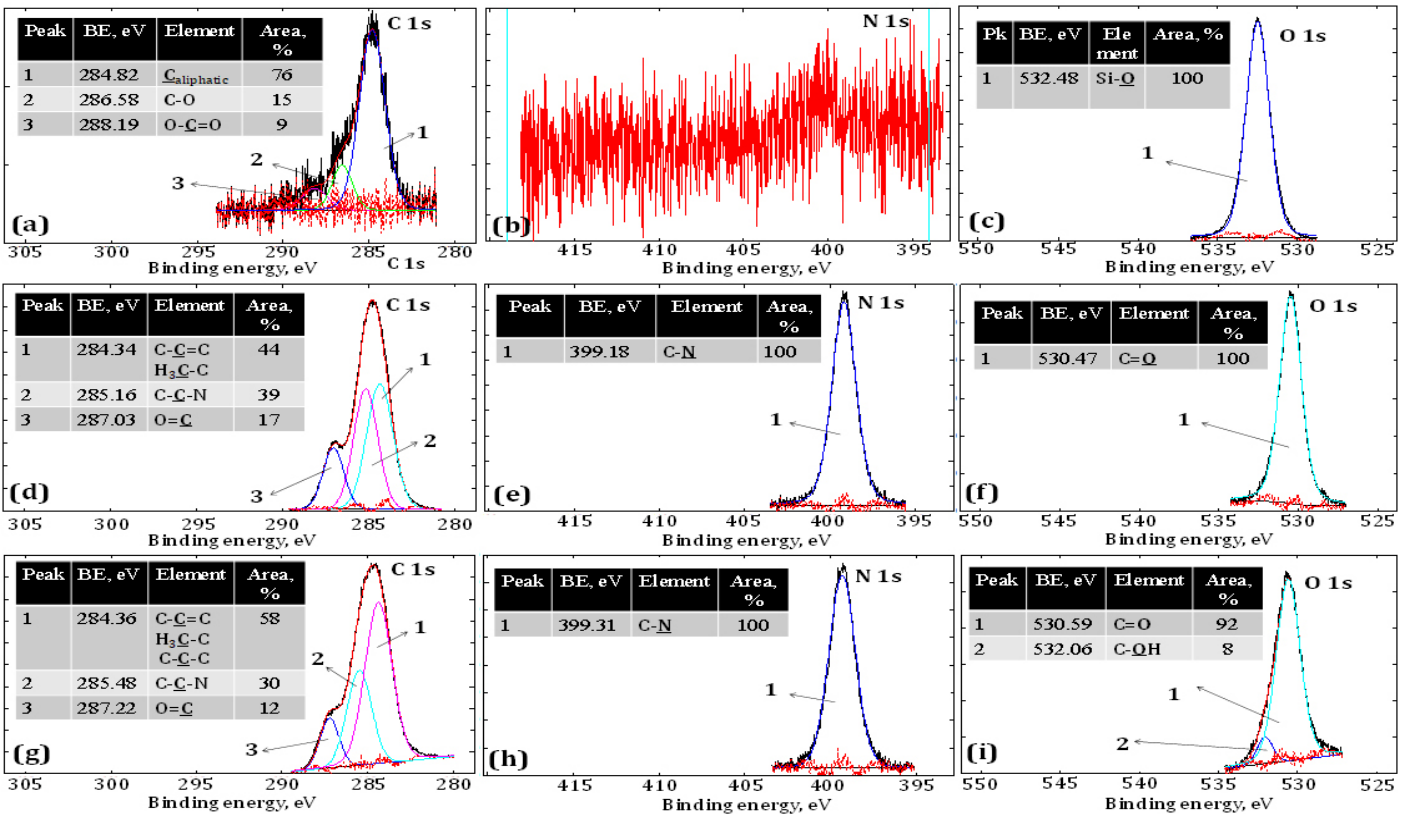

Figure 11. The high resolution $\mathrm{C} 1 \mathrm{~s}, \mathrm{~N}$ 1s, and $\mathrm{O} 1 \mathrm{~s}$ XPS spectra of (a-c) bare silicon wafer, (d-f) PEOXA-11\%EIBP after spin-coating, and (g-i) PEOXA-11\%EIBP after UV light irradiation at $365 \mathrm{~nm}$ followed by exposure to physiological (PBS) buffer.
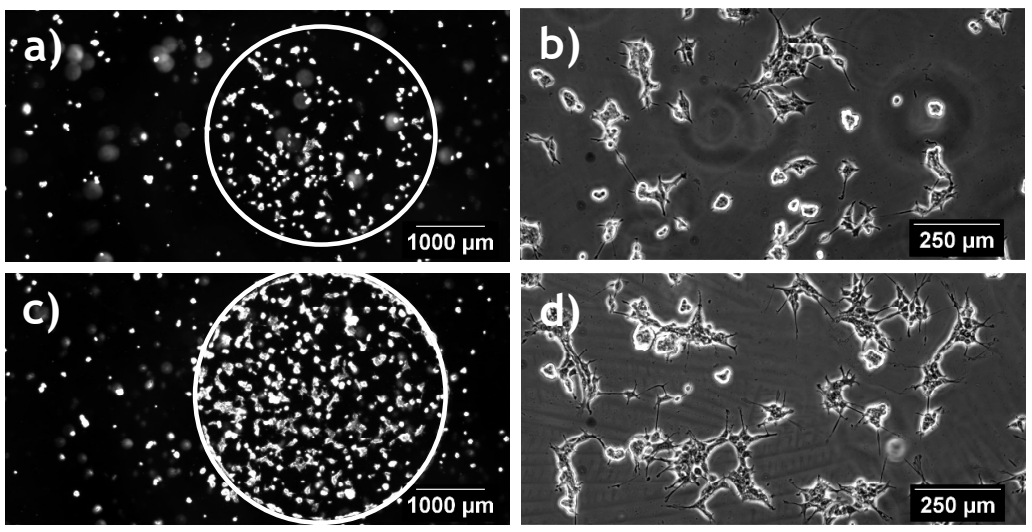

Figure 12. The (a \& c) 2x, and (b \& d) 10x-objective microscopic images of laminin-decorated PEOXA hydrogel films on PMMA plastics substrates. 
and allowed to dry after pre-irradiation of PEOXA film UV light $(365 \mathrm{~nm})$ at $(\mathrm{a} \& \mathrm{~b}) 5 \mathrm{~J} / \mathrm{cm}^{2}$ and $(\mathrm{c} \& \mathrm{~d}) 0 \mathrm{~J} / \mathrm{cm}^{2}$. Additional irradiation was then performed until the total energy dose for each surface reached $18 \mathrm{~J} / \mathrm{cm}^{2}$. The white solid circles were guides to the eye and represent laminindecorated PEOXA areas. The 10x-objective microscopic images were taken inside the circled areas.

It is seen in Figure 12 that the cells attached preferably to laminin-containing area (inside the circled area). Although cell attachment was also observed on the biopassive background outside the circled area, the cells were significantly more concentrated on the bioactive sites. Comparing Figure 12 a) and c), more cells attached on the laminin-containing area that was irradiated with higher UV light energy dose, i.e., more cells on image (c) compared to those on image (a). The reason for this observed phenomenon is that no pre-irradiation $\left(0 \mathrm{~J} / \mathrm{cm}^{2}\right)$ process to PEOXA film led to more active benzophenone crosslinker groups available for the covalent grafting of more laminin molecules on surface (c). Compared to surface (a), the PEOXA film was pre-irradiated $\left(5 \mathrm{~J} / \mathrm{cm}^{2}\right)$ before the drop-coating of laminin, thus less active benzophenone crosslinker groups were available for the covalent grafting of laminin molecules. Moreover, image (d) shows better cell growth compared to image (b), indicative of more flattened cell morphology. Round and small cells as shown in image b) indicated failure of cell attachment and growth on the surface.

The observed phenomenon was in agreement with literature (Loschonsky et al., 2008), which the authors reported increase of cell-adhesion with increasing amount of cell-adhesive molecules (RGD) on the surface, after incubation of the dual-functional surface in cell culture medium for $24 \mathrm{~h}$. The result was, somehow different, with our previous publication where PDMAA network was used as the biopassive platform (Pidhatika et al., 2019b). However, different polymers as bipassive coating were used. Furthermore, surface incubation in cell culture medium longer than $24 \mathrm{~h}$ has not been performed in this study.

\section{CONCLUSION}

The goal of the presented work was to build surface attached hydrogel layers on biomedical plastics that show dual-functional properties, i.e., exhibited a background having strongly cell-repellent properties and could exhibit in selected areas cell attractive properties. Poly(2-ethyl-2oxazoline) (PEOXA) with desired content of ethyleneimine benzophenone (EIBP) groups was used for substrate modification. The benzophenone units acted as photocrosslinkers to form PEOXA-based polymer networks that is covalently attached on the organic (plastics) substrate. When substrates that contained $\mathrm{C}-\mathrm{H}$ bonds on their surfaces were coated with the polymer and irradiated with UV light, the photoactive groups were activated and the reaction with carbon-hydrogen bonds nearby was initiated through $\mathrm{CH}$-insertion. Through this procedure, surfaceattached hydrogel layers were generated. Thus poly(methyl methacrylate) (PMMA) substrates can be modified and transformed into biopassive platforms with this method. Concerning the layer formation, it was found that energy of the UV light was important for layer stability. When the wavelength was low (thus the energy was high), some degradation occurred and the stability decreased. To obtain a dual-functional surface, cell adhesive locations need to be generated on the surfaces. To achieve this, the photoreaction during hydrogel generation was terminated before complete conversion of the photoactive groups. Onto this layer laminin as a well-known cell adhesion protein was coated before continuing the photoactivation process. This step leads to formation of a layer of covalently bound laminin. The results from dual-functional test on the hydrogel-modified PMMA plastics substrate validated, 1) the role of benzophenone of the photocrosslinker, 2) the role of laminin as bioactive (in this context cell adhesive) compound, 3) the role of PEOXA hydrogel as biopassive platform, and 4) the strategy that was suitable for the modification of any biomedical plastics (provided $\mathrm{C}-\mathrm{H}$ bonds are available) in tissue engineering applications.

\section{ACKNOWLEDGMENT}

The authors gratefully acknowledge the Alexander von Humboldt Foundation for financial support, and the group of Prof. Dr. Jürgen Rühe at the University of Freiburg for experimental facilities and supervision of the entire research stay in Germany during 2016-2018. The first author (Nan Zhao) was a master student who worked under supervision of Prof. Jürgen Rühe and the second author (Bidhari Pidhatika) during his master thesis project in the Laboratory for Chemistry \& Physics of Interfaces, IMTEK, University of Freiburg, Germany. The first author performed several parts of the experiments (especially those with surface modification and cell culture), and several data presented in this manuscript were adopted from his master thesis. The second author was the main contributor of this manuscript (research ideas, polymer synthesis, and writing of the entire manuscript).

\section{REFERENCES}

Bellis, S. L. (2011). Advantages of RGD peptides for directing cell association with biomaterials. Biomaterials, 32(18), 42054210. https://doi.org/10.1016/j.biomaterials.2011.02.029

Castner, D. G., \& Ratner, B. D. (2002). Biomedical surface science: Foundations to frontiers. Surface Science, 500(1-3), 28-60. https://doi.org/10.1016/S0039-6028(01)01587-4

Chen, Q., \& Thouas, G. A. (2015). Metallic implant biomaterials. Materials Science and Engineering: R: Reports, 87, 1-57. https://doi.org/10.1016/j.mser.2014.10.001

Chen, Y., Cao, W., Zhou, J., Pidhatika, B. Xiong, B., Huang, L., Tian, Q., Shu, Y., Wen, W., Hsing, I., \& Wu, H. (2015). Poly(1-lysine)-graft-folic acid-coupled poly(2-methyl-2oxazoline) (PLL-g-PMOXA-c-FA): A bioactive copolymer for specific targeting to folate receptor-positive cancer cells. ACS Applied Materials \& Interfaces, 7(4), 29192930. https://doi.org/10.1021/am508399w

Czuba, L. (2014). Application of Plastics in Medical Devices and Equipment. In K. Modjarrad, \& S. Ebnesajjad (Eds.), Handbook of polymer applications in medicine and medical 
devices (pp. 9-19). New York, USA: William Andrew Publishing. $\quad$ https://doi.org/10.1016/B978-0-323-22805$\underline{3.00002-5}$

Dahm, M., Chang, B., Prucker, O., Pierkes, M., Alt, T., Mayer, E., Rühe, J., \& Oelert, H. (2001). Surface attached ultrathin polymer monolayers for control of cell adhesion. The Annals of Thoracic Surgery, 71(5), 437-440. https://doi. org/10.1016/S0003-4975(01)02513-9

Dhende, V. P., Samanta, S., Jones, D. M., Hardin, I. R., \& Locklin, J. (2011). One-step photochemical synthesis of permanent, nonleaching, ultrathin antimicrobial coatings for textiles and plastics. ACS Applied Materials \& Interfaces, 3(8), 2830-2837. https://doi.org/10.1021/am200324f

Holzapfel, B. M., Reichert, J. C., Schantz, J., Gbureck, U., Rackwitz, L., Noth, U., Jakob, F., Rudert, M., Groll, J., \& Hutmacher, D. W. (2013). How smart do biomaterials need to be? A translational science and clinical point of view. Advanced Drug Delivery Reviews, 65(4), 581-603. https:// doi.org/10.1016/j.addr.2012.07.009

Kleber, C., Bruns, M., Lienkamp, K., Rühe, J., \& Asplund, M. (2017). An interpenetrating, microstructurable and covalently attached conducting polymer hydrogel for neural interfaces. Acta Biomaterialia, 58, 365-375. https:// doi.org/10.1016/j.actbio.2017.05.056

Körner, M., Prucker, O., \& Rühe, J. (2016). Kinetics of the generation of surface-attached polymer networks through C, H-insertion reactions. Macromolecules, 49(7), 24382447. https://doi.org/10.1021/acs.macromol.5b02734

Lambermont-Thijs, H. M. L., van der Woerdt, F. S., Baumgaertel, A., Bonami, L., Du Prez, F. E., Schubert, U. S., \& Hoogenboom, R. (2010). Linear poly(ethylene imine)s by acidic hydrolysis of poly(2-oxazoline)s: Kinetic screening, thermal properties, and temperature-induced solubility transitions. Macromolecules, 43(2), 927-933. https://doi. org/10.1021/ma9020455

Li, Y., Vergaelen, M., Schoolaert, E., Hoogenboom, R., \& De Clerck, K. (2019). Effect of crosslinking stage on photocrosslinking of benzophenone functionalized poly(2-ethyl-2-oxazoline) nanofibers obtained by aqueous electrospinning. European Polymer Journal, 112, 24-30. https://doi.org/10.1016/j.eurpolymj.2018.12.030

Loschonsky, S., Shroff, K., Wörz, A., Prucker, O., Rühe, J., \& Biesalski, M. (2008). Surface-attached PDMAA-GRGDSP hybrid polymer monolayers that promote the adhesion of living cells. Biomacromolecules, 9(2), 543-552. https://doi. org/10.1021/bm7010714

McCrackin, F. L., Passaglia, E., Stromberg, R. R., \& Steinberg, H. L. (2001). Treasure of the past VII: Measurement of the thickness and refractive index of very thin films and the optical properties of surfaces by ellipsometry. Journal of Research of the National Institute of Standards and Technololgy, 106(3), 589-603. https://doi.org/10.6028/ jres.106.025

Murata, H., Chang, B., Prucker, O., Dahm, M., \& Rühe, J. (2004). Polymeric coatings for biomedical devices. Surface Science, 570(1-2), 111-118. https://doi.org/10.1016/j. susc.2004.06.185

Padsalgikar, A. D. (2017). Applications of plastics in cardiovascular devices. In A. D. Padsalgikar (Ed), Plastics in medical devices for cardiovascular applications (pp. 133-176). New York, USA: William Andrew Publishing. https://doi.org/10.1016/B978-0-323-35885-9.00006-0

Pidhatika, B., Zhao, N., \& Rühe, J. (2019a). Development of surface-attached thin film of non-fouling hydrogel from poly(2-oxazoline). Journal of Polymer Research, 26, 21. https://doi.org/10.1007/s10965-018-1677-1

Pidhatika, B., Zhao, N., Zinggeler, M., \& Rühe, J. (2019b). Surface-attached dual-functional hydrogel for controlled cell adhesion based on poly(N,N-dimethylacrylamide). Journal of Polymer Research, 26, 69. https://doi. org/10.1007/s10965-019-1728-2

Prucker, O., Naumann, C. A., Rühe, J., Knoll, W., \& Frank, C. W. (1999). Photochemical attachment of polymer films to solid surfaces via monolayers of benzophenone derivatives. Journal of the American Chemical Society, 121(38), 87668770. https://doi.org/10.1021/ja990962

Sastri, V. R. (2014a). Materials used in medical devices. In V. R. Sastri (Ed), Plastics in medical devices (2 $2^{\text {nd }}$ ed., pp. 19-31). New York, USA: William Andrew Publishing. https://doi. org/10.1016/B978-1-4557-3201-2.00003-3

Sastri, V. R. (2014b). Material requirements for plastics used in medical devices. In V. R. Sastri (Ed), Plastics in medical devices ( $2^{\text {nd }}$ ed., pp. 33-54). New York, USA: William Andrew Publishing. https://doi.org/10.1016/B978-1-45573201-2.00004-5

Sastri, V. R. (2014c). Polymer additives used to enhance material properties for medical device applications. In V. R. Sastri (Ed), Plastics in medical devices ( $2^{\text {nd }}$ ed., pp. 55-72). New York, USA: William Andrew Publishing. https://doi. org/10.1016/B978-1-4557-3201-2.00005-7

Sastri, V. R. (2014d). Commodity thermoplastics: Polyvinyl chloride, polyolefins, and polystyrene. In V. R. Sastri (Ed), Plastics in medical devices ( $2^{\text {nd }}$ ed., pp. 73-102). New York, USA: William Andrew Publishing. https://doi.org/10.1016/ B978-1-4557-3201-2.00006-9

Scherag, F. D., Niestroj-Pahl, R., Krusekopf, S., Lücke, K., Brandstetter, T., \& Rühe, J. (2017). Highly selective capture surfaces on medical wires for fishing tumor cells in whole blood. Analytical Chemistry, 89(3), 1846-1854. https://doi. org/10.1021/acs.analchem.6b04219

Schuler, A., Prucker, O., \& Rühe, J. (2016). On the generation of polyether-based coatings through photoinduced $\mathrm{C}, \mathrm{H}$ insertion crosslinking. Macromolecular Chemistry and Physics, 217(13), 1457-1466. https://doi.org/10.1002/ macp. 201600065

Subbiahdoss, G., Kuijer, R., Grijpma, D. W., van der Mei, H. C., \& Busscher, H. J. (2009). Microbial biofilm growth vs. tissue integration: "The race for the surface" experimentally studied. Acta Biomaterialia, 5(5), 1399-1404. https://doi. org/10.1016/j.actbio.2008.12.011

Subbiahdoss, G., Pidhatika, B., Coullerez, G., Charnley, M., Kuijer, R., van der Mei, H. C., Textor, M., \& Busscher, H. J. (2010). Bacterial biofilm formation versus mammalian cell growth on titanium-based mono- and bi-functional coatings. European Cells and Materials, 19, 205-213. https://doi.org/10.22203/ecm.v019a20 
